\title{
LA REPRESENTACIÓN DEL APOYO DE LA PERSONA CON DISCAPACIDAD. EL NUEVO ESQUEMA DE LA CAPACIDAD JURÍDICA EN EL PERÚ
}

\begin{abstract}
Enrique Varsi Rospigliosi ${ }^{1}$
Resumen: Desde 2018, por el Decreto Legislativo 1384, Perú cuenta con un nuevo tratamiento de la capacidad en el Código Civil, que se adecua a las directrices en pro de la autonomía y la plena capacidad jurídica de las personas con discapacidad, concordando la legislación nacional a la Convención Internacional de los Derechos de las Personas con Discapacidad. El régimen de sustitución de la voluntad de las personas incapaces es reemplazado por un modelo social mediante apoyos y salvaguardias, un modelo inclusivo, democrático, acorde al respeto a los derechos humanos de todos los ciudadanos (dignidad e igualdad), partiendo del reconocimiento de la autonomía de la persona y su derecho a tomar sus propias decisiones, así como el derecho a equivocarse. Se desarrolla la función del apoyo en favor de la persona con discapacidad, analizando sus facultades de representación. Partimos del principio que el apoyo no reemplaza la manifestación de voluntad, solo la facilita e interpreta. Como una figura de asistencia, el apoyo colabora en una adecuada manifestación de voluntad, con el fin de que la persona con discapacidad ejerza su capacidad jurídica, disfrutando sus derechos y libertades.
\end{abstract}

Palabras clave: incapacidad, discapacidad, apoyos, salvaguardias, representación, curatela, interdicción, toma de decisiones

The representation of the support of the person with disability: The new scheme of legal capacity in Peru

\begin{abstract}
Capacity is a subject of transversal interest in Law, it is present in all its fields. It is an attribute that every subject has through which he/she can perform acts that are not prohibited. Since 2018, by Legislative Decree 1384, we have a new treatment of capacity in the Civil Code that is in line with the guidelines in favor of the autonomy and full legal capacity of persons with disabilities, aligning national legislation to the International Convention on the Rights of Persons with Disabilities. The regime of substitution of the will of incapable persons is replaced by a social model through supports and safeguards. We are facing an inclusive, democratic model, according to the respect for the human rights of all citizens (dignity and equality), based on the principle that people with disabilities have full exercise capacity in equal conditions in each and every aspect of their lives, recognizing their right to make their own decisions as well as the right to make mistakes. The function of the support in favor of the disabled person is developed, analyzing their powers of representation. We start from the principle that the support does not replace the manifestation of will, it only interprets it and collaborates in an adequate manifestation of will so that the person with disability can exercise his legal capacity, enjoying his rights and freedoms.
\end{abstract}

Keywords: incapacity, disability, support, safeguards, representation, guardianship, interdiction, decision making

A representaçáo do apoio à pessoa com incapacidade. O novo esquema da capacidade jurídica no Peru

Resumo: Desde 2018, pelo Decreto Legislativo 1384, o Peru conta com um novo tratamento da capacidade no Código Civil, que se adequa às diretrizes em prol da autonomia e da plena capacidade jurídica das pessoas com incapacidade, colocando de acordo a legislação nacional com a Convençáo Internacional dos Direitos das Pessoas com Incapacidade. O regime de substituiçáo da vontade das pessoas incapazes é trocado por um modelo social mediante apoios e salvaguardas, um modelo inclusivo, democrático, de acordo com o respeito aos direitos humanos de todos os cidadáos (dignidade e igualdade), partindo do reconhecimento da autonomia da pessoa e seu direito de tomar suas próprias decisóes, assim como o direito de equivocar-se. Desenvolve-se a funçáo de apoio em favor da pessoa com incapacidade, analisando suas faculdades de representaçáo. Partimos do princípio que o apoio não substitui a manifestação de vontade, somente a facilita e interpreta. Como uma figura de assistência, o apoio colabora para uma adequada manifestaçáo de vontade, com ela finalidade de que a pessoa com incapacidade exerça sua capacidade jurídica, desfrutando seus direitos e liberdades.

Palavras chave: incapacidade, invalidez, apoios, salvaguardas, representação, curatela, interdição, tomada de decisões

\footnotetext{
${ }^{1}$ Grupo de Investigación en Derecho Civil del Instituto de Investigación Científica de la Universidad de Lima, Perú. Universidad Nacional Mayor de San Marcos, Perú. ORCID: 0000-0002-7206-6522.

Correspondencia: evarsi@ulima.edu.pe
} 


\section{Introducción}

La capacidad y discapacidad tienen un nuevo tratamiento legislativo en el Perú.

El Código Civil (en adelante CC) fue reformado a través del DLeg. $1377^{2}$, que fortalece la protección integral de niños y adolescentes y, principalmente, por el DLeg $1384^{3}$, que reconoce y regula la capacidad jurídica de las personas con discapacidad en igualdad de condiciones, y su Reglamento, el DS. 016-2019-MIMP (en adelante Reg.); asimismo, por el DLeg. $1417^{5}$, que promueve la inclusión de las personas con discapacidad.

La nueva normativa nacional se adecua a las directrices de la autonomía y la plena capacidad jurídica de las personas con discapacidad, concordando la legislación nacional a la Convención Internacional sobre los Derechos de las Personas con Discapacidad ${ }^{6}$ (en adelante la Convención), que tiene por propósito proteger y asegurar el goce pleno en condiciones de igualdad de todos los derechos humanos, garantizar libertades fundamentales de todas las personas con discapacidad y promover el respeto de su dignidad. Plantea un cuestionamiento al término "incapacidad jurídica” y a la institución de la curatela e interdicción, partiendo de la premisa que éstas sustituyen a la voluntad, apartando al sujeto de sus decisiones. Lo que sugiere la Convención no es la sustitución sino, contrario sensu, la inclusión a través de instituciones de asistencia, como los ajustes razonables o el apoyo, para que las personas con discapacidad puedan expresar su fiel voluntad, i.e. promueve un cambio de paradigma que va de las decisiones por sustitución al soporte a las decisiones.

La Convención introduce el modelo social de la discapacidad, planteando que "la discapacidad no res-

\footnotetext{
${ }^{2}$ DOEP., 24/08/2018.

${ }^{3}$ DOEP., 04/09/2018.

${ }^{4}$ DOEP., 25/08/2019.

${ }^{5}$ DOEP., 13/09/2018.

${ }^{6}$ Aprobada por la Asamblea General de las Naciones Unidas en su Sexagésimo primer periodo de sesiones, mediante Resolución NRES/61/106, del 13 de diciembre de 2006, aprobada por el Congreso de la Republica mediante Resolución Legislativa $\mathrm{N}^{\circ}$ 29127 de fecha 30 de Octubre del 2007, publicado en el diario oficial EI Peruano el 01 de noviembre del 2007 y ratificada por el presidente de la Republica, según Decreto Supremo 073-2007-RE de fecha 30 de diciembre de 2007, publicado DOEP., 31/12/2007.
}

ponde a un aspecto inherente de la persona, sino a la interacción entre la deficiencia de la misma y las barreras sociales que impone la sociedad"(1).

La persona con discapacidad debe contar con un entorno que le permita el libre y pleno ejercicio de su capacidad y sus derechos, con base en el criterio de inclusión e igualdad. El individuo, más allá de sus debilidades, es un sujeto de derecho, un ser jurídico, que merece ser tratado en su dimensión integral de ser humano. Este criterio ha sido conceptualizado y ampliamente desarrollado por la bioética — véase Rozo Reyes(2) y Ramos Reyes(3) - , que consagra el valor de las personas basado en la aplicación de los principios bioéticos de solidaridad (ayuda y servicio mutuo), beneficencia (utilidad para la persona), justicia (igualdad y no discriminación) y autonomía (voluntad y autodeterminación)(4:59-60).

\section{Principios}

Las instituciones de asistencia en favor de las personas con discapacidad están sustentadas en los siguientes principios:

\subsection{Dignidad}

Como consagración de la persona, núcleo duro de esta.

Busca la preservación de la esencia del sujeto con discapacidad como ser humano. Su ser, realización y desarrollo.

La valoración integral del hombre ha determinado que, sin distinciones, se otorgue una garantía en la realización de sus derechos y en la generación de efectos en los actos jurídicos que realicen.

\subsection{Autodeterminación}

Prima la libre elección, la libertad de acceso, autonomía.

El ejercicio directo sobre la base de la voluntad de la persona con discapacidad.

A fin de coadyuvar con su capacidad de ejercicio, la persona mayor de edad (capaz o discapaz) tiene derecho a los ajustes razonable y designar personas de confianza; además, puede acceder de manera 
libre y voluntaria a los apoyos y salvaguardias (presentes o a futuro) que considere pertinentes para coadyuvar a su capacidad de ejercicio (art. 659-A, CC). Así, la persona con discapacidad puede solicitar o designar, de acuerdo con su libre elección, ajustes razonables o apoyos para el ejercicio de su capacidad jurídica (art. 45, CC).

\subsection{Igualdad}

No discriminación. Accesibilidad es sinónimo de igualdad.

Los sujetos, en similares condiciones, deben gozar de trato equiparitario, pues todos son iguales, independientemente si tienen o no una discapacidad; esto con base en el principio reconocido en el Código Civil "Las personas con discapacidad tienen capacidad de ejercicio en igualdad de condiciones en todos los aspectos de vida" (art. 3), "independientemente de si usan o requieren de ajustes razonables o apoyos para la manifestación de su voluntad" (art. 42, CC).

Es promover la participación e inclusión, eliminar barreras. Esto se logra con las medidas de accesibilidad, las que, insistimos, son sinónimo de igualdad. Estas "medidas, que garantizan la detección y eliminación de las barreras existentes en el entorno para que las personas con discapacidad puedan tener acceso a los bienes y servicios en condiciones de igualdad con las demás personas, a fin que puedan vivir en forma independiente y participar plenamente en todos los aspectos de la vida" (num. 6, art. 2, Reg. 016).

No cabe ningún tipo de distinción, y es que toda persona (capaz o discapaz) tiene capacidad de goce (titularidad) y ejercicio de sus derechos (realización).

\subsection{Coadyuvan a la manifestación de la voluntad}

Estos mecanismos de asistencia de la persona con discapacidad logran, en su esencia, lo siguiente (tabla 1):
Contribuyen a la realización de la voluntad (del querer) en su:
Manifestación

Interpretación

Comprensión

\begin{tabular}{|l|l|}
\hline $\begin{array}{l}\text { Facilita y garantiza el } \\
\text { goce y ejercicio de: }\end{array}$ & $\begin{array}{l}\text { Derechos } \\
\text { Voluntad } \\
\text { Preferencias } \\
\text { Capacidad jurídica }\end{array}$ \\
\hline $\begin{array}{l}\text { Permiten la } \\
\text { realización de actos } \\
\text { para que produzcan } \\
\text { efectos jurídicos: }\end{array}$ & $\begin{array}{l}\text { Informa de sus } \\
\text { efectos } \\
\text { Orientan en su }\end{array}$ \\
\hline $\begin{array}{l}\text { Actuación del apoyo } \\
\text { conforme a: }\end{array}$ & $\begin{array}{l}\text { Sus facultades } \\
\text { Mandato } \\
\text { encomendado }\end{array}$ \\
\hline Prevenir el: & $\begin{array}{l}\text { Abuso } \\
\text { Influencia indebida }\end{array}$ \\
\hline
\end{tabular}

Tabla 1. Fuente: Elaboración propia.

\subsection{Reconocimiento de capacidad jurídica}

Es una obligación. La capacidad es propia del sujeto, la tiene por su propia calidad y naturaleza; la esencia de su ser lo hace dignatario del goce.

Por ello, su reconocimiento es una obligación; además, se trata de un reconocimiento puro e incondicional, integral e irrestricto.

Así tenemos que:

- La capacidad se desarrolla sobre la base de la igualdad.

- La capacidad jurídica incluye la capacidad de goce y de ejercicio.

- Reconocer la capacidad de las personas con discapacidad es obligación de todos.

- Los ajustes razonables y apoyos no disminuyen el estatus de la persona, permiten la realización de actos para que estos produzcan efectos jurídicos.

- La designación de un apoyo no es exigible para el reconocimiento y ejercicio de un derecho.

\section{Apoyo y salvaguardias}

Es apoyo es la asistencia a la persona con discapa- 
cidad, que le permite llevar a cabo su manifestación de la voluntad para la generación de efectos jurídicos en su favor. Es un facilitador y orientador, asiste a la persona con discapacidad. Su actuar no condiciona el reconocimiento de la capacidad, esta permanece, como debe ser. Esto a punto tal que el apoyo es libremente elegido (cuando la persona con discapacidad puede expresar voluntad) y, por excepción, los designa el juez (cuando no se puede expresar voluntad).

El apoyo logra que la persona con discapacidad llegue a entender por sí mismo, Intellectus ipse, la trascendencia de sus actos. Esa es su principal labor, de cooperación.

La función del apoyo es la asistencia de la persona con discapacidad, entre sus acciones tenemos (art. 659-B, CC):

- Facilitar el ejercicio de los derechos.

- Orientar en la realización de actos que produzcan efectos jurídicos.

- Apoyo en la:

- Manifestación e interpretación de la voluntad requerida.

- Comunicación, comprensión y consecuencias de los actos jurídicos.

La participación personal y directa de la persona con discapacidad es la regla, y su no partición -i.e. que sea el apoyo el que intervenga- es la excepción. El apoyo no sustituye ni suple ni complementa. Permite que la persona con discapacidad se informe, evalúe y decida, manifestando su $\operatorname{voluntad}(5)$. Es decir, acompaña en los momentos esenciales en la toma de decisión de la persona con discapacidad.

Las salvaguardias son medidas para garantizar el respeto de los derechos, la voluntad y las preferencias de la persona que recibe apoyo; previenen el abuso y la influencia indebida de quien brinda tales apoyos; así como evitar la afectación o poner en riesgo los derechos de las personas asistidas (art. 659-G, CC).

La función de las salvaguardias es dar seguridad a través de medidas (art. 659-G, CC):

- Que el apoyo actúe conforme al mandato encomendado.

- Garantizar en la persona que recibe apoyo el respeto de los derechos, la voluntad y las preferencias.

- Evitar la afectación o poner en riesgo los derechos.

- Prevenir el abuso y la influencia indebida por parte de quien brinda tales apoyos.

Aseguran que la persona designada como apoyo actúe conforme al mandato encomendado, respetando los derechos, la voluntad y las preferencias de la persona que cuenta con apoyo y asegurando que no exista influencia indebida.

\section{Representación}

La regla es que el apoyo no representa a la persona con discapacidad, la excepción es que la representación sea delegada (representación voluntaria) o declarada por el juez (representación legal).

Es necesario precisar que "El apoyo no tiene facultades de representación, salvo en los casos en que ello se establezca expresamente por decisión de la persona con necesidad de apoyo o el juez en el caso del artículo 659-E7” (art. 659-B), i.e. en la escritura pública o en la sentencia de designación debe establecerse expresamente (Reg. 016):

- Las facultades de representación (num. 9.2., art. 9).

- Los actos para los cuales se faculta dicha representación (num. 11.3., art. 11).

Esto en la línea que se está otorgando poderes al apoyo que actuará en favor de la persona con discapacidad, lo que implica que se trate de un poder especial, por lo que deben especificarse uno a uno

${ }^{7}$ FE DE ERRATAS, DOEP., 08/12/2018. El texto del DLeg. 1384 indicaba al artículo 569, artículo este que había sido 569 derogado por el mismo DLeg. 1384 en su Disposición complementaria derogatoria, Única, lit. b. Este craso error, Bardales (2018, p. 210) lo denomina "Una contradicción normativa: la reafirmación de la vigencia del artículo 569 y la derogación del artículo 569 en la misma norma". 
los actos para los cuales ha sido facultado (art. 155 CC, principio de literalidad).

El apoyo escapa a la figura de curador, tutor o de representante, y es que la persona con discapacidad es una persona capaz. Atenta contra su dignidad humana pretender imponerle una sustitución a su voluntad (curatela) o en cabeza otros realizar sus actos (representación).

Así, tenemos las siguientes diferencias entre apoyo, curador y representante (tabla 2):
Bien dice Torres Vásquez(6:97-98) que la ley "no elimina la figura de la representación, sino que relega su aplicación residual para los casos más graves en los que el discapacitado no pueda manifestar su voluntad y resulte imposible la aplicación del sistema de apoyos".

Conforme al artículo 659-B del Código Civil, procede designar apoyo y otorgar facultades de representación en el mismo instrumento público ${ }^{8}$.

\footnotetext{
8 Res. 1135-2019-SUNARP-TR-L, del 02/05/2019 sobre nombramiento de apoyo y salvaguardias.
}

\begin{tabular}{|c|c|c|}
\hline Apoyo & Curador & Representante \\
\hline $\begin{array}{l}\text { Asiste a la persona con } \\
\text { discapacidad para que ejerza sus } \\
\text { derechos }\end{array}$ & $\begin{array}{l}\text { Ejerce todos los derechos del } \\
\text { curado (una forma de muerte } \\
\text { civil) }\end{array}$ & Ejerce los derechos delegados \\
\hline Colabora & Protege y sustituye & $\begin{array}{l}\text { Sustituye, actúa en nombre de su } \\
\text { representado }\end{array}$ \\
\hline $\begin{array}{l}\text { Conoce a la persona con } \\
\text { discapacidad, esta a su lado }\end{array}$ & $\begin{array}{l}\text { No conoce a la persona con } \\
\text { discapacidad, actúa como un } \\
\text { buen padre de familia }\end{array}$ & $\begin{array}{l}\text { Conoce al representado, actúa de } \\
\text { acuerdo con el mandato }\end{array}$ \\
\hline $\begin{array}{l}\text { Cuando tiene representación, } \\
\text { decide tomando en cuenta } \\
\text { opinión, voluntad y preferencias } \\
\text { de la persona con discapacidad }\end{array}$ & $\begin{array}{l}\text { Decide por cuenta propia y de lo } \\
\text { que cree que es mejor }\end{array}$ & $\begin{array}{l}\text { Obra de acuerdo con facultades } \\
\text { conferidas }\end{array}$ \\
\hline $\begin{array}{l}\text { Presta una ayuda en la } \\
\text { manifestación e interpretación de } \\
\text { la voluntad }\end{array}$ & $\begin{array}{l}\text { Sustituye, siendo el curador el que } \\
\text { expresa su voluntad }\end{array}$ & $\begin{array}{l}\text { El representante lleva a cabo actos } \\
\text { por un interés particular, vía } \\
\text { delegación }\end{array}$ \\
\hline $\begin{array}{l}\text { Puede impugnar los actos o } \\
\text { decidir acabar con el apoyo (salvo } \\
\text { los obligatorios) }\end{array}$ & $\begin{array}{l}\text { El curado no puede impugnar a su } \\
\text { curador }\end{array}$ & $\begin{array}{l}\text { Puede dejar sin efecto la } \\
\text { representación }\end{array}$ \\
\hline $\begin{array}{l}\text { Se elige o designa libremente y } \\
\text { de forma voluntaria; cuando es } \\
\text { designado, el juez debe ceñirse a } \\
\text { ciertos parámetros }\end{array}$ & $\begin{array}{l}\text { Salvo el caso de curador nombrado } \\
\text { con anterioridad (Autotutela), es } \\
\text { designado por el juez y prima la } \\
\text { prelación }\end{array}$ & Se le elige libremente \\
\hline Protege el ejercicio de los derechos & $\begin{array}{l}\text { Protege a la persona buscando } \\
\text { su rehabilitación, administra su } \\
\text { patrimonio }\end{array}$ & $\begin{array}{l}\text { Ejerce en nombre de otro sus } \\
\text { derechos }\end{array}$ \\
\hline Sujeto a control (salvaguardias) & No sujeto a control & \\
\hline $\begin{array}{l}\text { Es por tiempo determinado y es } \\
\text { fijado por la propia persona o por } \\
\text { el juez }\end{array}$ & Es por tiempo indeterminado & $\begin{array}{l}\text { Puede ser por tiempo determinado } \\
\text { o indeterminado }\end{array}$ \\
\hline \multicolumn{2}{|l|}{ Libro de Derecho de familia } & Libro de Acto jurídico \\
\hline
\end{tabular}

Tabla 2. Fuente: Elaboración propia. 


\subsection{Clases}

La representación del apoyo puede ser:

\subsubsection{Delegada}

Es la voluntariamente otorgada.

- En el apoyo futuro. La escritura pública de designación de apoyos debe contener "la determinación de los alcances y/o facultades de la persona designada como apoyo" (lit. d, num. 30.1., art. 30, Reg. 016).

- En el apoyo presente. "La persona con discapacidad puede otorgar a la persona designada como apoyo, facultades de representación, conforme a las reglas generales de representación contenidas en el Código Civil" (num. 11.1., art. 11, Reg. 016).

A criterio de Bregaglio(7), tenemos los siguientes criterios para tener en cuenta para la designación voluntaria de apoyos (tabla 3):

\begin{tabular}{|l|l|}
\hline Necesidad & $\begin{array}{l}\text { El apoyo debe designarse para } \\
\text { actos jurídicos (uno o varios de } \\
\text { su misma especie) }\end{array}$ \\
& $\begin{array}{l}\text { Dependiendo del tipo de acto } \\
\text { jurídico, podría determinarse } \\
\text { una duración del apoyo }\end{array}$ \\
\hline Imparcialidad & $\begin{array}{l}\text { El apoyo no podría beneficiarse } \\
\text { del acto a realizar (conflicto de } \\
\text { interés) } \\
\text { No debe haber indicios de } \\
\text { posible influencia indebida } \\
\text { del apoyo a la persona con } \\
\text { discapacidad } \\
\text { Designación de salvaguardias }\end{array}$ \\
\hline $\begin{array}{l}\text { Control } \\
\text { Supervisión }\end{array}$ & $\begin{array}{l}\text { Establecer } \\
\text { para controlar al apoyo } \\
\text { periódicamente }\end{array}$ \\
\hline
\end{tabular}

Tabla 3. Fuente: Elaboración propia.

\subsubsection{Declarada}

Es la judicialmente establecida, llamada excepcional.

El juez puede otorgar facultades de representación a los apoyos cuando la persona con discapacidad (art. 659-E) no pueda manifestar su voluntad o se encuentre en estado de coma y no hayan designado un apoyo (num. 9, art. 44, CC).

Todas las propuestas coinciden en que, frente a situaciones como discapacidades intelectuales severas o profundas, estado de coma permanente, estados de Alzheimer muy avanzados, en las que no es posible, incluso mediante apoyos, obtener la voluntad de la persona, la actuación de un representante se torna necesaria(8:40).

El representante legal implica limitar, mejor dicho sustituir, la capacidad jurídica, lo cual está prohibido de forma expresa por la Convención.

\subsubsection{Falta de voluntad}

Es la carencia de voluntad. Cuando el sujeto no puede expresar su deseo, intención y querer.

Sostiene Espinoza(9:1345) que, bajo la fórmula genérica "persona con discapacidad que no puede expresar su voluntad" se comprendería a los faltos de discernimiento y a quienes adolecen de deterioro o retraso mental.

\subsubsection{Estado de coma}

Conocido como estado vegetativo persistente o vigilia sin conciencia. Es una privación de discernimiento, se carece de posibilidad de manifestar voluntad.

\section{Labor del juez en la designación de apoyo con facultades}

En la designación excepcional de apoyo con facultades de representación, el juez deberá llevar a cabo una labor especial para obtener la voluntad de la persona que recibirá el apoyo, para ello (num. 11.2., art. 11, Reg. 016) realizará los esfuerzos reales, considerables y pertinentes, y prestará las medidas de accesibilidad y ajustes razonables.

Cumplida con esta labor y no habiéndose obtenido la manifestación de voluntad, el juez estará facultado para designar apoyo con facultades. Este es el carácter residual de la representación del apoyo, ultima ratio. Las facultades que se confieran deben ser las necesarias, determinándose de forma 
detallada la forma de ejecución de lo actos jurídicos que estarán a su cargo.

En este caso debe verificar que las facultades de representación sean necesarias para el ejercicio y protección de sus derechos, lo cual funciona como una salvaguardia.

Téngase en cuenta que el juez designa al apoyo más conveniente; a quien más conoce a la persona con discapacidad, a quien esté en mejor capacidad para desempeñar la labor, a quien mejor puede "representar", de manera fiel y real, la voluntad que pudo haberse sido manifestada por la persona con discapacidad. Esto es una característica delimitada de la representación del apoyo.

Ejercicio de la facultad de representación por el apoyo

El apoyo ejercerá la facultad de representación en favor de la persona con discapacidad respetando (art. 659-B, y num. 2, art. 2, nums. 11.2., 11.3., art. 11, Reg. 016):

- Los derechos.

- La voluntad y preferencias.

- Y conforme al criterio de la mejor interpretación de la voluntad:

- Considerando la trayectoria de vida de la persona.

- Las previas manifestaciones de voluntad en similares contextos.

- La información con la que cuenten las personas de confianza de la persona asistida.

- Cualquier otra consideración pertinente para el caso concreto.

Asegura Bariffi(8:40) que el representante no puede decidir sobre su mejor criterio, debe tener en cuenta la voluntad presunta de la persona; es así que, citando a Agustina Palacios(10), indica que ella prefiere hablar de "acciones de representación" y no meramente de representación. Ello en razón de que son acciones concretas, excepcionales, pre- vistas en la ley, controladas por orden judicial y que, en última instancia, "deben siempre estar destinadas a que la decisión que finalmente se adopte respete la historia de vida, los valores, y las preferencias de la persona concreta". Esto funciona como una salvaguardia.

\subsection{Eficacia de los actos}

El apoyo puede actuar "con" o "en nombre" de la persona con discapacidad.

Por regla, el apoyo no tiene facultades de representación, salvo en los casos en que ello se establezca expresamente por decisión de la persona con necesidad de apoyo o por el juez, art. 659-B.

Respecto de la eficacia de sus actos, tenemos dos escenarios:

Cuando actúa sin representación: Es el caso en que el apoyo no tiene representación, i.e. la persona con discapacidad no ha delegado facultad alguna, siendo la persona con discapacidad quien decide realizar todos los actos para sí.

Cuando actúa con representación: Es el caso en que el apoyo tiene representación, i.e. la persona con discapacidad o el juez ha delegado facultad a tercera persona.

Respecto de los actos del representante, excediendo sus facultades tenemos los siguientes casos:

- Por exceso del límite de las facultades conferidas.

- Por defecto realiza actos que no estaba facultado, falsus procurator.

A estos dos, Priori(11:622) los llama "ausencia de legitimación representativa”, y se da cuando se aparece el supuesto representante (tuvo facultades o nunca las tuvo) o cuando el representante actúa más allá de sus facultades.

- Violación de las facultades conferidas, es el abuso del poder representativo y se da en los casos de actuar en conflicto de interés con el representado, lesionar su interés o cuando el representado se aleja de las instrucciones(11:625). 
Si el apoyo excede de sus facultades, el acto sería ineficaz por aplicación del artículo 161 del Código.

\section{El modelo de apoyos y la representación legal}

Para este tema nos basamos en Bariffi(8), quien nos dice que el modelo de apoyos previsto por el artículo 12(3) de la Convención se presenta como una alternativa del modelo de representación clásico y vigente en los sistemas jurídicos de los Estados Partes. Se pregunta: ¿̇ignifica ello que no puede darse la representación en el marco de un sistema de apoyos? Para plantear una respuesta presenta tres modelos diferentes, partiendo de una noción de apoyos caracterizada por el reconocimiento del derecho de la persona a tomar sus propias decisiones.

\subsection{Acciones de representación en el marco de un modelo de apoyo}

Son de orden legal o judicial, impuestas. Funcionan en última instancia frente a situaciones límites (estado de coma o Alzheimer) en las que no es posible, ni mediante apoyos, obtener la voluntad de la persona. Situaciones ante las cuales es necesaria la participación de un representante, quien deberá actuar teniendo en cuenta la voluntad presunta de la persona, de allí que se llamen "acciones de representación" (Palacios), respetándose la historia de vida, los valores y las preferencias de la persona con discapacidad.

Téngase en cuenta los tres elementos que la componen: i) representación de tipo legal, ii) son excepcionales y específicas y iii) el representante debe demostrar diligencia debida: no debe actuar a su mejor criterio sino teniendo en cuenta la voluntad presunta.

\section{Aplicabilidad}

En nuestro medio se da en los casos de designación judicial de apoyos, según el art. 659-E, cuando la persona:

- No pueda manifestar su voluntad o

- Se encuentre en estado de coma y no haya designado un apoyo (num. 9, art. 44).
El apoyo solo tiene facultades de representación cuando lo establece expresamente la persona con necesidad de apoyo o el juez, en el caso del artículo 659-E (art. 659-B). En estos casos, la escritura pública o en la sentencia de designación debe establecer expresamente las facultades de representación (num. 9.2., art. 9, Reg. 016) y los actos para los cuales se faculta dicha representación (num. 11.3., art. 11, Reg. 016).

\section{Compatibilidad con los estándares que recogen la Convención}

A pesar de que la representación legal implica una limitación, mejor dicho una sustitución de la capacidad jurídica - lo que está prohibido de forma expresa por la Convención-, todas las propuestas coinciden en que, frente a situaciones como discapacidades intelectuales severas, estado de coma permanente, estados de Alzheimer muy avanzados, en las que no es posible, incluso mediante apoyos, obtener la voluntad de la persona, la actuación de un representante se torna necesaria (8:40). Por lo tanto, sería compatible con la Convención siempre que no sea discriminatorio y no se presente como un acto de sustitución por motivos de discapacidad.

\subsection{Representación voluntaria generada en el marco de un modelo de apoyos}

Es libre. Complementaria a la anterior. Es un régimen de apoyos que incluye acciones de representación mediante la suscripción de acuerdos de representación. Se da en lo casos en que una persona decide con antelación, de forma libre y voluntaria, quien lo representará a futuro. Es el caso de los poderes preventivos, la autotutela, instrucciones anticipadas o el testamento vital (living will).

\section{Aplicabilidad}

En nuestro medio tenemos a:

Designación de apoyo a futuro: Llamada directiva anticipada mediante la que "Toda persona mayor de 18 años puede designar ante notario el o los apoyos necesarios en previsión de requerir en el futuro asistencia para el ejercicio de su capacidad jurídica" (art. 659-F).

Facultad para nombrar su propio curador: A tra- 
vés de esta institución, una persona adulta mayor puede anticipadamente establecer la protección de su persona y bienes ante su propia discapacidad futura, facultándosele a que (i) nombre su propio curador; (ii) indicar sus facultades o (iii) disponer quiénes no pueden ser designados como tales, art. 568-A. Un sector de la doctrina establece que el art. 568-A, del ha sido derogado tácitamente por el art. 659-F, por incompatibilidad, y en aplicación del principio de posterioridad, al regular este último artículo la designación de apoyos a futuro. Esta situación denota una mala técnica legislativa. Sin embargo, habiéndose mantenido vigente, solo sería aplicable para los casos de los incs. 4 al 7 del art. 44 .

Y en el caso de Colombia, art. 21 de su Código Civil con las directivas anticipadas.

\section{Compatibilidad con los estándares que recogen la Convención}

El texto del artículo 12 (2) y (3) de la Convención, si bien prohíbe la sustitución en la toma de decisiones de personas con discapacidad, dicho concepto no es absoluto sino desde una perspectiva de no discriminación. En este sentido, en la medida que un poder no sea discriminatorio y no se presente como un acto de sustitución por motivos de discapacidad, los poderes preventivos y acuerdos de representación de forma genérica para cualquier persona no resultarían contrarios a la Convención.

\subsection{Representación excepcional fuera del modelo de apoyos}

Opera cuando la capacidad restringida es ineficaz.

Es la que sigue Bariffi(8), considerando que, si bien hay incompatibilidad absoluta entre el modelo de los apoyos y la representación legal (específica y excepcional), ello no implica que una persona con discapacidad no pueda, viéndosele limitada su capacidad, habilitársele a una persona a decidir en su nombre. Ello siempre que dicho procedimiento sea aplicable fuera del marco de los apoyos, pero con las salvaguardias necesarias que eviten discriminación por motivo de discapacidad.

\section{Aplicabilidad}

En nuestro medio se mantiene la interdicción y la curatela única y exclusivamente para casos específicos, señalados en los incs. 4 al 8 del art. 44 (art. 564) como sujetos con capacidad restringida.

Los tenemos reconocidos en los siguientes códigos civiles: Argentina (art. 32), Brasil (art. 1767) e Italia (arts. 404 y 427), y en Irlanda con la Ley de apoyo en la toma de decisiones - Assisted Decision Making (Capacity) Act, del 30 de diciembre de 2015-, que contempla tres instituciones fundamentales: la toma de decisiones con apoyo y la codecisión y el apoderamiento preventivo (enduring powers of attorney). Sin embargo, puede darse el caso de que una persona que no haya adoptado previsión alguna devenga en la práctica incapaz de adoptar decisiones, situación en la que el juez nombrará un representante en la toma de decisiones.

\section{Compatibilidad con los estándares que recogen la Convención}

La representación legal, incluso aquella de tipo específica y excepcional, es incompatible con el modelo de apoyos. Sin embargo, la Convención no prohíbe que se implemente algún procedimiento para declarar incompetente a una persona siempre que se haga sobre la base de un criterio que consagre tres elementos: a) legitimidad, b) proporcionalidad y c) no discriminación. Este criterio no solo surge de la aplicación de la Convención, sino también respecto de todos los tratados de derechos humanos.

Una persona con discapacidad puede ser declarada incompetente para tomar una decisión en la medida en que pueda quedar contemplada en el supuesto objetivo previsto para cualquier persona. No procede declarar la incompetencia por una razón de discapacidad.

\section{Participación}

La mera designación del apoyo no implica que la persona con discapacidad pierda autonomía, puede realizar actos sin la partipación del apoyo designado (12, p. 73) en la medida en que su participación no sea obligatoria y pueda expresar su deseo y generar efectos jurídicos deseados, sin necesidad del apoyo. Es necesario destacar que la ley promueve la participación de la persona con disca- 
pacidad en la celebración de actos jurídicos de forma directa y personal. Aquello siempre que pueda manifestar su voluntad, esto en el marco del reconocimiento de la autodeterminación, el derecho a la toma de decisiones, el derecho a equivocarse y el libre desarrollo de la personalidad (proyecto de vida) que tiene todo sujeto, en armonía con los principios de la Convención(13).

La regla es que la propia persona con discapacidad realice el acto jurídico, teniendo el derecho de contar con un apoyo que no participa en el acto jurídico. Este apoyo solo colabora en el entendimiento, facilitación o interpretación de la manifestación de voluntad. La no participación del apoyo en el acto jurídico es la regla y su partición es la excepción. La participación del apoyo solo será "obligatoria en caso se haya determinado en el documento de su designación" (num. 12.1., art. 12, Reg. 016) i.e. en la escritura pública o sentencia; en tal situación se presenta como un elemento esencial —essentiala negotti, un requisito o elemento de validez del acto jurídico que realice la persona con discapacidad en el que deberá intervenir — necesariamente - el apoyo. De esta manera "Durante la realización del acto que produzca efectos jurídicos, debe dejarse constancia de la participación del apoyo solo cuando se facilite o interprete la manifestación de voluntad" (num. 12.2., art. 12, Reg. 016). En estos dos casos está justificada su participación.

En los casos que la participación del apoyo sea obligatoria, exigible por ley, por estar establecido en el documento de su designación, y este no participe, implicará una manifestación de voluntad incompleta, afectando la validez del acto jurídico. Así, el acto jurídico realizado por la persona con discapacidad será nulo con base en el art. V del Título Preliminar y al inc. 8, art. 219 CC, que consagra la nulidad virtual por contravenir normas de orden público (como son las normas de capacidad), en especial contrariar el num. 12.1., art. 12, Reg. 016. Es de considerar que la referida norma no establece sanción expresa frente a su incumplimiento, por lo que debemos recurrir a la nulidad virtual o tácita.

La no participación del apoyo, en el acto que debió intervenir, puede darse por diversas razones:
- Es el propio apoyo quien decide no participar, situación ante la cual sí responde por las consecuencias que genere.

- La persona con discapacidad evita su participación. Ante esta situación el apoyo no responde.

Este nuevo requisito de validez — la participación del apoyo en el acto jurídico realizado por la persona con discapacidad - opera como una salvaguardia. La intención de la norma es que el apoyo coadyuve en la manifestación de la voluntad, que la exteriorización de la voluntad interna sea la deseada. En consecuencia, esta participación es un requisito de validez protectivo, pensado en que los efectos deseados del acto jurídico beneficien a la persona con discapacidad, que las consecuencias jurídicas sean su sentir.

En el régimen peruano no contamos con una norma como la colombiana (art. 199 , L. 1996-2019) que trata la naturaleza jurídica de la participación y de los efectos de la no participación, pero los nums. 12.1 - 2., art. 12, Reg. 016 tienen el mismo espíritu: la exigibilidad expresa de la participación del apoyo, la misma que debe ser siempre en beneficio y favorabilidad para la persona con discapacidad. El apoyo no reemplaza a la persona con discapacidad, solo cumple con su participación como exigencia de validez del acto jurídico.

Esta es la nueva dimensión de la teoría del acto jurídico que amerita un estudio particular. Sic et simpliciter.

\footnotetext{
${ }_{9}^{9}$ Artículo 19. Acuerdos de apoyo como requisito de validez para la realización de actos jurídicos. La persona titular del acto jurídico que cuente con un acuerdo de apoyos vigente para la celebración de determinados actos jurídicos, deberá utilizarlos, al momento de la celebración de dichos actos jurídicos, como requisito de validez de los mismos.

En consecuencia, si la persona titular del acto jurídico lleva a cabo los actos jurídicos especificados por el acuerdo de apoyos, sin hacer uso de los apoyos allí estipulados, ello será causal de nulidad relativa, conforme a las reglas generales del régimen civil.

Parágrafo. Lo dispuesto en el presente artículo no puede interpretarse como una obligación para la persona titular del acto jurídico, de actuar de acuerdo al criterio de la persona o personas que prestan el apoyo. En concordancia con lo establecido en el numeral 3 del artículo 40 de la presente ley, los apoyos deben respetar siempre la voluntad y preferencias de la persona titular del acto jurídico, así como su derecho a tomar riesgos y a cometer errores.
} 


\section{Conclusiones}

Luego del análisis, hemos arribado a las siguientes conclusiones:

- Las instituciones de asistencia en favor de las personas con discapacidad están sustentadas en los principios de dignidad, autodeterminación, igualdad, y coadyuvar a la manifestación de voluntad y reconocimiento de la capacidad jurídica.

- La persona con discapacidad debe contar con un entorno que le permita el ejercicio de su capacidad y sus derechos, sobre la base del criterio de inclusión y de igualdad, criterios desarrollados por la bioética que priorizan el valor de las personas en aplicación de los principios bioéticos de la no maleficencia, beneficencia, justicia y autonomía.

- Todo sujeto, sin excepción, capaz o discapaz, tiene capacidad jurídica para el goce y ejercicio de sus derechos, independientemente que usen o requieren de ajustes razonables o apoyos para la manifestación de su voluntad.

- En ciertos casos, el sujeto requiere de asistencias para su desarrollo e interacción. Estas juegan un rol crucial para la integración social de la persona con discapacidad, de forma que pueda expresar su voluntad y cumplir con la transcendencia jurídica de los actos jurídicos deseados.

- El apoyo asiste a la persona con discapacidad. Le permite llevar a cabo su manifestación de la voluntad para la generación de efectos jurídicos en su favor. No reemplaza la manifesta- ción de voluntad, solo la facilita e interpreta; i.e. como una figura de asistencia, colabora para que sea adecuada y la persona con discapacidad ejerza su capacidad, disfrutando sus derechos y libertades. El apoyo no representa a la persona con discapacidad; la excepción es que la representación sea delegada (representación voluntaria) o declarada por el juez (representación legal).

- Las salvaguardias aseguran la labor del apoyo, con el fin de que actúe conforme al mandato encomendado, respetando los derechos, voluntad y preferencias de la persona asistida, evitando el abuso e influencia indebida por quien brinda apoyo.

- Se promueve la participación de la persona con discapacidad en la celebración de actos jurídicos (directa y personalmente) manifestando su propia voluntad, esto en el marco del reconocimiento de la autodeterminación, el derecho a la toma de decisiones, el derecho a equivocarse y el libre desarrollo de la personalidad (proyecto de vida) que tiene todo sujeto, en armonía con los principios de la Convención.

Agradecimientos: El presente artículo ha sido realizado en el marco del Grupo de Investigación en Derecho Civil del Instituto de Investigación Científica de la Universidad de Lima, Perú, y del Proyecto de Investigación de esta misma Universidad PI.61.006.2020: "El nuevo tratamiento de la capacidad en el Derecho Civil peruano. Un necesario análisis transversal de la capacidad en los distintos libros del Código Civil”, IP. Enrique Varsi Rospigliosi. 
La representación del apoyo de la persona con discapacidad - Enrique Varsi Rospigliosi

\section{Referencias}

1. Mamani F. Decreto Legislativo No 1384: Un importante paso para el ejercicio de la capacidad juridica de las personas con discapacidad. 2018, septiembre [citado en junio de 2020]. Instituto de Democracia y Derechos Humanos (Idehpucp). Disponible en https://idehpucp.pucp.edu.pe/notas-informativas/decreto-legislativo-no-1384-un-importante-paso-parael-ejercicio-de-la-capacidad-juridica-de-las-personas-con-discapacidad/\#_ftn3

2. Rozo Reyes C. Principios bioéticos y discapacidad: la perspectiva de su inclusión en las políticas públicas. Revista Colombiana de Bioética 2011; 6(2): 26-44.

3. Ramos Pozón S. Una visión más realista de la convención sobre los derechos de las personas con discapacidad. Acta Bioethica 2017; 23(1), 119-128.

4. Varsi Rospigliosi E. Derecho genético: Principios generales. 5ed Lima: Grijley; 2013.

5. Varsi Rospigliosi E, Santillán R. Manifestación de voluntad de las personas con discapacidad en la teoría general del acto jurídico y la nueva perspectiva basada en los apoyos. Un estudio de Derecho peruano. Actualidad Jurídica Iberoamericana 2021; 14: 1060-1081.

6. Torres Vásquez A. La capacidad jurídica en el nuevo artículo 3 del Código Civil. Gaceta Civil y Procesal Civil 2018; 65: 51-100.

7. Bregaglio R. La reforma en capacidad jurídica en Perú (PPT). Diplomatura de estudio sobre reformas en capacidad jurídica de personas con discapacidad en América Latina 2020. Lima.

8. Bariffi F. El modelo de toma de decisiones con apoyos: De la teoría a la práctica. En: A. Kraut, Derechos y salud mental 2020 (Vol. II). Buenos Aires: Rubinzal Culzoni: 241-288.

9. Espinoza Espinoza J. Derecho de las personas. Concebido y personas naturales. 8a ed. Lima: Instituto Pacífico; 2019.

10. Palacios A. Seminario Capacidad jurídica, Discapacidad y Derechos Humanos. Universidad Carlos III de Madrid, 15 al 18 de febrero de 2010. Disponible en http://www.tiempodelosderechos.es

11. Priori Posada G. Representación directa sin poder. En: Muro Rojo M, Torres Carrasco M. Código Civil comentado. Lima: Gaceta Jurídica; 2020.

12. Mejía Rosasco R. La implementación de la Convención de las personas con discapacidad en la función notarial. Fondo editorial del Colegio de notarios del Perú; 2019.

13. Varsi Rospigliosi E. El nuevo tratamiento del régimen de la capacidad en el Código Civil peruano. Acta Bioethica 2019; 2(25): 199-213.

Recibido: 16 de abril de 2021

Aceptado: 18 de mayo de 2021 